\title{
UN SISTEMA PENAL EN UN ESTADO PRETENDIDAMENTE SOCIAL Y EN UNA SOCIEDAD POCO DEMOCRÁTICA
}

\section{A LEGAL SYSTEM IN AN ALLEGEDLY SOCIAL STATE AND INA SLIGHTLY DEMOCRATIC SOCIETY}

DOI: 10.5533/1984-2503-20102301

Roberto Bergalli

\section{RESUMO}

Por que Sistema? É possível falar de um "sistema penal" nas condições de homogeneidade disciplinária desde as quais se expõem até o presente seus conteúdos? Análise das duas vertentes configuradoras de um sistema penal y os distintos tipos de conhecimento aplicáveis aos seus estudos. Perspectivas disciplinárias que se ocupam de ambas as vertentes. Em todos estes casos, sempre se alude a "comportamentos" humanos diante das regras (normas) jurídicas. A criação de tais regras, suas necessárias interpretações e posteriores aplicações. Sua ulterior interpretação e imediata aplicação por meio das instâncias predispostas para o exercício concreto do controle penal.

Palavras-chave: Sistema penal, perspectivas disciplinárias, normas jurídicas.

\section{RESUMEN}

¿Por qué Sistema? ¿Es posible hablar de un "sistema penal" en las condiciones de homogeneidad disciplinaria desde las que se exponen hasta el presente sus contenidos? Análisis de las dos vertientes configuradoras de un sistema penal y los distintos tipos de conocimiento aplicables para sus estudios. Perspectivas disciplinarias que se ocupan de ambas vertientes. En todo caso, siempre se alude a "comportamientos" humanos frente a reglas (normas) jurídicas. La creación de tales

\footnotetext{
${ }^{1}$ Esta intervención tiene como fin recordar a Louk Hulsman. Gran exponente del pensamiento abolicionista, desaparecido de reciente. Un ser humano de excepción. Presentada en el I Congreso sobre Sistema Penal, organizado por Estudiantes y Graduados, en la Facultad de Derecho (UBA), en 2, 3 y 4 septiembre 2009 (Buenos Aires).
} 
reglas, sus necesarias interpretaciones y sus posteriores aplicaciones. Su ulterior interpretación e inmediata aplicación por medio de las instancias predispuestas para el ejercicio concreto del control penal.

Palabras-clave: Sistema penal, perspectivas disciplinárias, normas jurídicas.

\section{ABSTRACT}

Why System? Is it possible to speak of a "legal system" in conditions of disciplinary evenness that rules its substance so far? Analysis of two characterized aspects of a legal system and of different types of knowledge applicable to their study. Disciplinary perspectives that fit both aspects. In all the cases, references to human "behaviors" facing legal rules (norms) are made. Creating these rules, their needed interpretations and succeeding applications. Its following interpretation and immediate application through predisposed proceedings to the concrete exercise of legal control.

Key-words: Legal system, disciplinary perspectives, legal norms.

\section{RÉSUMÉ}

Pourquoi Système ? Est-il possible de parler de «système pénal » dans les conditions d'homogénéité disciplinaire à partir desquelles se manifeste sa substance jusqu'à nos jours ? Analyse des deux versants qui configurent un système pénal et des différents types de connaissance applicables à leur étude. Perspectives disciplinaires s'intéressant à ces deux versants. Dans tous les cas, l'on fait référence à des « comportements humains » face aux règles (normes) juridiques. La création de telles règles, leurs nécessaires interprétations et leurs applications postérieures. Leur interprétation ultérieure et immédiate application par l'intermédiaire des instances prédisposées à l'exercice concret du contrôle pénal.

Mots-clés : Système pénal, perspectives disciplinaires, normes juridiques.

\section{¿Porqué Sistema?}

Es casi una tradición utilizar la expresión "sistema penal" en los lenguajes de las disciplinas que se ocupan de los delitos y de las penas. Pero, ¿a qué se alude con la palabra "sistema" y qué se pretende incluir o designar conceptualmente con ella? Pienso que las respuestas que pueda proporcionar en esta intervención a estos dos 
interrogantes no complacerán a buena parte de quienes emplean habitualmente la expresión.

No obstante, me parece importante introducir una digresión frente a semejante uso y he de comenzar por lo más sencillo pero básico, diciendo que la expresión "sistema penal" es la combinación de un substantivo -sistema- originariamente tomado de un lenguaje ajeno a las disciplinas jurídicas y de un adjetivo -penal- que denota sin duda el carácter calificativo de las consecuencias que en el marco de los Estados de derecho se aplican a las conductas humanas que se demuestran como acciones $u$ omisiones punibles.

La expresión sistema o sistemas ha inundado todos los lenguajes presumiblemente científicos, desde finales del s. XIX. Ha avanzado desde la biología hasta la cibernética, reemplazando el empleo del concepto de "organismo" en la primera, y ha facilitado la construcción de una "teoría de los sistemas" (von Bertalanffy 1968; 1976 y ss.) común para diversos ámbitos disciplinarios. En el marco de esta teoría se encuentran los sistemas cerrados y abiertos. En tanto los primeros están aislados del medio circundante y pese a que sus elementos se muevan en su interior según las leyes físicas la tendencia en los sistemas cerrados será la del máximo desorden (entropía), mas a un cierto punto el proceso finalizará y se alcanzará un estado de equilibrio. Los segundos o sistemas abiertos son propios de los organismos vivientes, los que precisamente por estar incorporando y eliminando materia en continuidad, jamás alcanzan un equilibrio químico o termodinámico. Sin embargo, la teoría no ha dejado que se pronuncie de modo tajante esa división entre sistemas cerrados y abiertos, como tampoco se profundice la contradicción entre la ley física de la disipación de la materia y la de la evolución darwiniana que explicaría biológicamente los sistemas abiertos, por lo que unos y otros tipos de sistemas pueden ser intercambiables.

Por lo demás y vinculado con lo dicho, una teoría de la comunicación asentada en la noción general de la información no se explica sino es sobre la base del principio de retroalimentación (Feedback) y cualquier sistema, en particular cerrado, funciona mediante ciertos mecanismos retroalimentadores que justifican el comportamiento teleológico, tanto en las máquinas, como en los organismos vivos cuanto en los sistemas sociales (cfr. von Bertalanffy cit.: 41-42). De tales maneras, la eventual 
entropía (medida del desorden interno) de todo sistema favorece la alimentación del mismo y no sólo internamente, sino también hacia el exterior.

Así las cosas, el conocimiento humano y en particular el conocimiento científico ha avanzado, por lo general, también desde una perspectiva sistémica tratando de soslayar la complejidad que promueven los fenómenos bajo observación. En el terreno de las disciplinas sociales y humanas la aplicación de tal perspectiva ha sido francamente fructífera. Desde la propuesta de Emile Durkheim (funcionalista) para observar macroscópicamente a las sociedades, por cierto bastante rudimentaria pero utilísima en la segunda mitad del s. XIX, mediante la cual fue posible vislumbrar las diferentes "funciones" que cumplían en todo sistema social las distintas actividades, grupos y aportes humanos, pasando por la de Talcott Parsons y sus seguidores (estructural-funcionalistas), hasta llegar a la de Niklas Luhmann (funcionalestructuralista), la visión sistémica adoptó carta de ciudadanía en aquel grupo de disciplinas. El gran aporte de una tal perspectiva sistémica ha constituido en que, a medida que la complejidad de los sistemas sociales ha aumentado, ella ha contribuido para facilitar la observación de las partes constitutivas de todo el sistema y los fenómenos que las afectan, como asimismo poder percibirlas en sus mayores y menores dimensiones. Asimismo, la comprensión de todo sistema social, desde el conocimiento de la retroalimentación a la que propenden los diversos sub-sistemas que los conforman, según la óptica luhmanniana, ha avanzado hasta hacer penetrar la observación en los intersticios que componen la vida social e institucional. En tales sentidos, la teoría jurídico-penal, con su gran capacidad de abstracción, permite reducir y sintetizar en expresiones lingüísticas que se conforman como reglas jurídicas aquellas situaciones punibles que se producen en la vida cotidiana, facilitando su captación y absorción en fórmulas legales, como base de todo sistema penal. La disciplina que se ocupa de ello ha recibido la denominación de dogmática penal y, naturalmente, ello no es casual pues la naturaleza del conocimiento que ha desarrollado ha sido así: dogmático, es decir, concluyente, imperioso, incuestionable e incontrastable con situaciones, fenómenos o componentes extraños al subsistema. Su objeto de conocimiento no va más allá de los elementos que componen las reglas, teniendo en cuenta las normas en que ellas se apoyan. Su fundamento se ajusta en descifrar el contenido jurídico de dichas reglas y normas. Sus límites están fijados por el ámbito en que se mueven los análisis, cuales son: los elementos normativos, sus relaciones entre sí y quizá con los que configuran otras reglas o normas del sistema 
jurídico al que pertenecen. El método de tales análisis se entiende como formando parte de lo que se conoce como metodología jurídica. Lo señalado constituye el substrato de toda epistemología jurídico-penal. Conviene todavía destacar que dentro del marco de límites en que se mueve la dogmática jurídico-penal es cuando se hace admisible la intervención punitiva, fuera de ellos no es plausible: esta es la función de garantía que le corresponde asegurar a todo sistema penal moderno y que debe exaltar en el análisis de los elementos que configuran las reglas jurídico-penales.

\section{La vertiente abstracta o estática de todo sistema penal}

Empero, por lo menos son bastante dudosas y, por tanto, debatibles las capacidades de comunicación y retroalimentación de que disponen los sub-sistemas jurídico-penales en las diferentes sociedades. No obstante, es obvio que todo subsistema jurídico debería poseer ambas capacidades, en la medida que la comprensión de los problemas suscitados en toda sociedad puedan tener una canalización procesal. Para ello, debe ser indispensable la aplicación de unas reglas jurídicas producidas desde la percepción de la presunta punibilidad de ciertas situaciones. En este punto es donde se hace visible la existencia de diferentes intereses sociales que promueven la producción de las reglas, en uno u otro sentido, para facilitar la reducción de la complejidad o del problema social que subyace a las conductas punibles. En consecuencia, el momento de creación o producción de reglas jurídicas determina la constitución o el comienzo de lo que usualmente se denomina como "sistema penal", en la tradición continental-europea. Esta tarea tiene asimismo como objeto plasmar el sentido racional que posee el empleo del castigo penal y que emergiendo del lluminismo ha atravesado la Modernidad tratando de alcanzar fines retributivos y preventivos, partiendo de fundamentos éticos o simplemente jurídicos, salvaguardando los derechos humanos fundamentales. He aquí sintéticamente expresado el concepto de razón jurídica que ha presidido la existencia de todo sistema penal moderno, o sea: hacer previsible lo que puede acontecer cuando se constata la comisión de un delito, pero también establecer, mediante fórmulas de procedimiento, el ejercicio de un control no sólo penal sobre hechos y conductas, sino también sobre cómo y quienes ejercen tal control.

Mas, como se ha dicho, si la configuración o el comienzo de un sistema penal está determinado por la existencia de reglas jurídicas, pues entonces para la 
conformación final de dicho sistema como tal es necesario que esas reglas jurídicas sean oportunamente aplicadas, es decir empleadas en el análisis jurídico-penal de las situaciones que, en principio, parecen adecuarse a las descripciones ideales que de ellas hacen las reglas en cuestión. Este último proceso -la aplicación de las reglas válidas- es la esencia de un paso decisivo en el destino de las normas jurídicas, conocido como el de la "interpretación" del derecho, el cual facilita el tránsito de una situación y de unos comportamientos cuyas realidades fácticas jamás podrán ser reproducidas pero sí serán objeto de una adecuación a una realidad jurídica; es decir que todo proceso interpretativo no convierte o transforma los hechos bajo juzgamiento, pero sí permite su descripción y definición desde el derecho. En cualquier caso, en los Estados constitucionales de derecho, tanto la creación como la interpretación de reglas jurídicas tendentes a la tipificación de comportamientos humanos como figuras de delitos, han estar encaminadas por los principios de justicia social que deben guiar la actuación de las políticas públicas, las cuales se ajustan a la forma social del Estado. Esto al menos acontece en los Estados que mediante constituciones escritas así lo han establecido, como en el caso de España, donde la Constitución Española de 1978 ha establecido que "España se constituye como un Estado social y democrático de Derecho, que propugna como valores superiores de su ordenamiento jurídico la libertad y la justicia, la igualdad y el pluralismo político" (cfr. Art. 1.1 Constitución Española). Es decir que la creación de las reglas jurídico-penales, como expresión legislativa de la democracia parlamentaria y como cualesquiera otras del ordenamiento jurídico, ha de estar orientada por los principios que encaminan al Estado español como uno social. No ocurre algo diferente en los Estados y con las constituciones que en Europa continental optaron por la forma-social (así en la República Federal de Alemania, donde mediante el pár. 20 [1] de sus Principios constitucionales se estableció que la República Federal de Alemania es "un Estado federal, democrático y social" o en la Repubblica Italiana donde entre los Principi Fondamentali de la Costituzione de 1947, el Art. 3, segundo párrafo establece que: É compito della Repubblica rimuovere gli stacoli di ordine economico e sociale, che, limitando di fatto la libertà e l'eguaglianza dei cittadini, impediscono il pieno sviluppo della persona umana e l'effettiva partecipazione di tutti i lavoratori all’organizzazione politica, economica e sociale del Paese).

La Constitución de la Nación Argentina, si bien no contiene una declaración expresa para configurar al Estado bajo la forma social, en cambio admite (en su art. 14 bis) que los ciudadanos pueden ejercer un número de derechos a los que califica como 
"sociales", todos ellos vinculados con el trabajo humano. Mientras, en lo referido a las atribuciones del Congreso (C. N. Cap. IV), se regulan una serie de derechos (art. 75, inc. 19) indudablemente relacionados con la dimensión social de los individuos. Semejantes preceptos constitucionales, si bien afirmativos en lo que atañe a la función social que se espera debe cumplir el derecho, no son terminantes en lo relativo a la adopción de la forma social para el Estado argentino y si bien ciertas necesidades de los ciudadanos se corporizan como "derechos" es discutible si los mismos forman parte de la constitución material del Estado argentino. A la luz de la visible desprotección de alguna de ellas, como en particular el propio trabajo, la salud, la educación, la vivienda, presentar al Estado argentino como uno que ha adoptado y pone en práctica la forma social se convierte, de momento, en una pretensión. Semejantes desprotecciones, no obstante, no constituyen la substancia de una tipificación penal que tenga en cuenta con coherencia la naturaleza de bienes jurídicos colectivos que se agravian. Son innumerables las situaciones que cotidianamente se producen y que ponen ostensiblemente en evidencia la falta de atención o respeto a las necesidades que motivan el surgimiento de derechos sociales agredidos. Pero, es comprensible que si se hiciera un recurso repetido a la creación de tipos de delitos relativos a la violación de esos derechos sociales, en la medida en que se constata la desatención a ellos, el panorama punitivo sería impensablemente vasto y el sistema penal estaría por entero dedicado a la persecución de sus autores, ya empresarios, políticos o funcionarios. Ante un cuadro semejante como el que presenta la desprotección de los llamados derechos sociales en la República Argentina y la tentación que pueda nacer de perseguir penalmente a los responsables de tal desprotección, en el caso que ese desamparo fuera previsto por reglas jurídico-penales, siempre sería preferible el cuestionamiento democrático de las políticas públicas que no corrigen el abandono de los declamados principios de justicia social, antes de producir una inflación punitiva. Ciertamente, esta preferencia debería estar apoyada en un ejercicio de democracia política que no es muy fuerte en el presente.

\section{La segunda vertiente: concreta o dinámica}

Sin embargo, la cristalización de posibles situaciones de la vida real en tipos legales no agota, en absoluto, el despliegue de los sistemas penales. Para que esto acontezca es necesario que se pongan en funcionamiento las intervenciones previstas que puedan llevar a una descarga punitiva o a una exención de posible castigo penal 
en aquellas situaciones en las que presumiblemente se reúnen los elementos necesarios para que la amenaza penal pueda concretarse. En pocas palabras, basta decir que el sistema penal no se consume al reconocer que las acciones $u$ omisiones que realizan ciertos seres humanos encuentran su acogida penal, en modo abstracto o estático, en unas y otras reglas del ordenamiento jurídico-penal o que existen otras que describen el comportamiento de aquellas instancias encargadas de encarrilar el procedimiento que permitirá llegar a la absolución o condena del acusado. Mientras, por su parte, habrá todavía otros preceptos, incluidos en leyes específicas que, dependiendo de la forma política del Estado (federal, centralizado, por regiones y por autonomías) disponen la forma de actuar o el comportamiento de los encargados de disponer y ejecutar las consecuencias punitivas previstas para quienes resulten condenados (leyes que regulan la composición y funcionamiento de la Policía, los cuerpos que la integran y el comportamiento esperado de sus miembros; las que organizan las actividades de los juzgados y tribunales que componen el llamado Poder Judicial, los órganos que gobiernan la administración de justicia; y, por fin, las que establecen la existencia y formas de actuar de las cárceles y de los funcionarios penitenciarios).

Ello así pues la articulación de un sistema penal, como se ha adelantado, no se concreta sobre la única existencia de reglas, normas, leyes e incluso constituciones. La segunda vertiente del sistema penal que estoy ahora intentando describir se corporiza en comportamientos humanos, los de quienes están encargados de poner en marcha, de manera concreta, las actividades previstas en esa segunda vertiente.

Los momentos o instancias en los que se concreta la aplicación de las reglas jurídicas que configuran esa segunda vertiente de todo sistema penal moderno han de estar asimismo previstas en las leyes u ordenamientos legales que regulan lo que usualmente se denomina como el procedimiento penal. A efecto de verificar cómo se expresa esta segunda vertiente debe tenerse en cuenta que en el inicio o decurso de este procedimiento ha de tener lugar la actuación de uno/os cuerpo(s) públicos de seguridad o policía judicial, los que bien pueden ser los iniciadores de una posterior actuación jurisdiccional al recibir la noticia de la posible comisión de un delito, o bien van a intervenir recogiendo pruebas o elementos relativos a dicho delito al impulso de unos fiscales o representantes del Ministerio público fiscal, promotores de la actuación jurisdiccional inmediata y también encargados de velar por la legalidad de estas y otras 
posteriores etapas del procedimiento penal. La intervención de un juez que eventualmente dirija (según el orden dispuesto por esa ley de procedimiento), oriente o controle la investigación criminal y la posterior actuación de un juzgado, tribunal o instancia jurisdiccional que determine la efectiva comisión de un delito y la posible responsabilidad del autor o autores del mismo son, asimismo, expresiones de esa vertiente concreta o dinámica de los sistemas penales modernos, tanto en el ámbito del derecho continental europeo y áreas de su influencia como también en el del Common Law, obviamente con matices y diferencias.

Así deberían denominarse las dos vertientes de todo sistema penal moderno: una abstracta 0 estática y otra concreta o dinámica en tanto la primera se manifiesta respecto a eventuales hechos punibles y sus actores de forma indeterminada, sólo jurídicamente descriptiva en los aspectos o elementos formales que supuestamente deben reunir los eventuales hechos y personas que pueden caer como delitos y autores responsables bajo una determinación jurisdiccional; mientras, la segunda se refiere a la intervención de aquellas instancias predispuestas a la averiguación de hechos, efectivamente realizados y sus encuadramientos como figuras de delitos, cuanto asimismo al procesamiento y eventuales condenas o absoluciones de quienes en origen aparezcan imputados de haberlos cometido (cfr. por todas y múltiples lugares donde ha estado explicado este concepto de sistema penal, Bergalli 1993).

Manifiesto es que en relación a la primera vertiente se hace relevante el conocimiento jurídico-teórico o comúnmente denominado como dogmático, mientras que para la segunda de esas vertientes es imprescindible un conocimiento empíricopráctico. Ello así pues, la intervención de la instancia policial, la actuación de las fiscalías, la actividad jurisdiccional y el cumplimiento o ejecución de las consecuencias punitivas se traducen en decisiones como frutos de comportamientos humanos, los que más allá de satisfacer las tareas asignadas a cada una de esas funciones del sistema penal, son la expresión de la propia visión que de la función tienen quienes la ejercen. He aquí un punto neurálgico y decisivo para completar la noción de sistema penal, en relación al cual poca atención le prestan los juristas, al menos los que pertenecen al área cultural hispano hablante. Estoy convencido, a partir del sondeo que realizo desde tiempo en un elevado número de facultades de derecho de nuestra área que en el conjunto de la educación legal a la que se les somete a los estudiantes, se presta muy escasa atención a la adopción de conocimientos en el terreno de las disciplinas que 
pueden explicar el comportamiento de los policías, de los jueces o de los funcionarios penitenciarios. De la investigación emerge que los juristas hispano-hablantes adquieren un conocimiento experto, de naturaleza dogmática, de las reglas jurídicas. Pero, no se forman en los terrenos de la sociología de las organizaciones que les permitiría entender las instituciones desde las cuales se aplican las reglas jurídico-penales y se concreta el control penal. Tampoco adquieren conocimientos de psicología social y antropología cultural con los cuales podrían inferir o explicarse el porqué de los comportamientos de los policías, los jueces y fiscales, o de los funcionarios penitenciarios cuando estos se expresan como el resultado de unas interpretaciones de las reglas jurídico-penales disímiles o contrastantes de las que habitualmente hace el dogmático.

No estoy proponiendo un estudio diferenciado de los sistemas penales, creo que ambas vertientes que he intentado distinguir deben formar parte de una misma comprensión sobre aquellos. Y si bien si estoy proponiendo el empleo de perspectivas disciplinarias que provienen de distintos fundamentos epistemológicos, no estoy propiciando un tratamiento diferenciado de las dos vertientes que he presentado. Tampoco hay en mi propuesta una tentativa de ciencia global o total del derecho penal, de corte lisztiano, en la que el derecho penal debe servir para determinar la responsabilidad de los autores y la política criminal para desarrollar sus indicaciones en el tratamiento de los condenados pues, como acaba de demostrar Muñoz Conde (al igual que lo hizo con Mezger), el aporte de von Liszt fue de suma utilidad para los posteriores usos que el nazismo hizo del mismo.

No creo, sin embargo que el unilateral conocimiento con que se abordan las situaciones y los problemas, sobre todo de índole social que en el presente agobian a los sistemas penales, sea el único motivo de las incoherencias que estos revelan. La discordancia que cada día se patentiza más entre las declaraciones de principios liberales por parte de la teoría jurídico-penal y la admisión de ciertos avances de un derecho penal autoritario (como acontece con las propuestas muy firmes de admitir la limitación o recortes de garantías para ciertos acusados, quienes por su condición de excluidos, pasan a investir la condición de "enemigo interno") es la prueba más clara de cuánto y hasta qué punto se ha extraviado la razón jurídica que presidía los modelos de sociedades de inclusión social. 
Acontece algo semejante cuando contemplamos los modos de actuación de las instancias de aplicación del sistema penal. Las Declaraciones Internacionales de Derechos Humanos, las Constituciones políticas, las leyes y códigos penales, como también los propios instrumentos legales que regulan la actuación de tales instancias, exaltan la necesidad que los sistemas penales salvaguarden la integridad física y psíquica de quienes resulten acusados y sean objeto de investigación policial, procesamientos judiciales o sometidos a prisión. Empero, constatamos a diario que los policías torturan, los jueces y tribunales no acogen las denuncias o las archivan sin investigar y los funcionarios penitenciarios son asimismo proclives a los malos tratos hacia los presos, cuando no causantes de verdaderas tragedias carcelarias. No estoy aludiendo únicamente a cuanto acontece en Argentina que ya es mucho. Ocurre en todo el planeta, pero lo que ya no asombra es que también en las sociedades con Estados constitucionales, democráticos y sociales de derecho ello sea algo muy habitual, a comenzar por la que se ha conocido como la gran democracia del norte de América. Quizá se haya llegado a un punto sin retorno con las experiencias de los últimos conflictos en países del mundo árabe; las denominadas "guerras preventivas" de la década de 1990 y las posteriores intervenciones en Irak o Afganistán han dejado prueba de irracionalidad punitiva. La tragedia del 11 septiembre 2001 (nine/eleven) en New York y otras posteriores en Europa continental, abrieron sin piedad la caja de los truenos. Lo ocurrido con los llamados Combatientes Enemigos, sus reclusiones en Guantánamo y las torturas a que fueron sometidos (las que comienzan a ser investigadas jurisdiccionalmente por la administración Obama), como los traslados (extraordinary Renditions) posteriores de sospechosos a través de aeropuertos europeos (denunciados por el eurodiputado Fava), impulsaron el empleo indiscriminado de medios penales que hasta entonces no se aceptaba usarlos y se consideraban propios de un control punitivo pre-moderno. No nos asombremos si hoy, en Europa, sobre todo en los países del área mediterránea (Italia, Francia y España), como custodios para evitar el ingreso de inmigrantes sin papeles se aplica a sus respectos una barbarie punitiva propia de una razón perversa, no obstante que en su esencia esa conducta podría constituir una infracción administrativa, pero hoy es considerado delito de "inmigración clandestina" por la ley italiana (pachetto sicurezza).

Por otra parte son tan habituales las actividades policiales ligadas a los intereses de las organizaciones criminales que basta sólo mencionarlas; también los comportamientos de jueces y fiscales guiados u orientados por intereses políticos de 
partidos o de protección de utilidades empresariales; como, asimismo, la tutela o la preferente atención que los funcionarios penitenciarios prestan a los jefes de bandas o recomendados por dirigentes políticos, recluidos en las instituciones. La ignorancia de todo ello o la imposibilidad de verificarlos podrían evitarse o alertarse si existiesen conocimientos empíricamente constatados. Para todo ello, hay que potenciar la investigación de campo acerca de cómo actúan los policías, cómo lo hacen los jueces y cómo los funcionarios penitenciarios; cuáles son y a qué intereses responden sus decisiones sobre hechos y autores punibles. Obviamente que desarrollar este tipo de investigación choca contra los corporativismos, los espíritus de cuerpo y las ideologías profesionales que alientan unos y otros encomendados de interpretar y aplicar las reglas jurídico-penales. Romper estos muros que aíslan estas instancias o instituciones de todo sistema penal, corriendo el velo que cubre el acontecer dentro de ellas, sería el resultado que podría alcanzarse. Mas, para ello, primero deberían verificarse empíricamente las decisiones y comportamientos de policías, fiscales, jueces y funcionarios penitenciarios a través de unas metodologías de participante-observador con las que se constate si efectivamente esos comportamientos se ajustan al acatamiento a los deberes de funcionarios que se espera aquellos cumplan. En segundo lugar, si tales comportamientos son violatorios de las garantías y los derechos humanos que el sistema penal debe salvaguardar a los sujetos sometidos al control, entonces corresponde presentar las pertinentes denuncias y darlas a conocimiento. Puede confiarse que semejante proceder terminaría con el secreto bajo el cual se cubren las irregularidades y los abusos. Mas, asimismo, con ello sería plausible alcanzar una cierta democratización de cualquier sistema penal la que, por ahora, no parece posible.

\section{REFERENCIAS}

Bergalli, R. (Co-autor y coord.). (1993). Sistema Penal y Problemas Sociales, Valencia: tirant lo blanch (Alternativa).

Bertalanffy, L. Von. (1968; 1976). General System Theory, Foundations, Development, Applications, New York: George Braziller. Primera versión en castellano, ulteriores reimpresiones (trad. J. Almela), México D. F.: Fondo de Cultura Económica. 